\title{
VIOLÊNCIA EM MEIO ESCOLAR NO BRASIL: UMA ALTERNATIVA FORMATIVA PARA PROFESSORES E FUTUROS PROFESSORES
}

\author{
Marilda da SILVA ${ }^{1}$ \\ Elaine Cristina SCARLATTO ${ }^{2}$
}

\begin{abstract}
RESUMO: Neste estudo, procuramos mostrar, a partir de artigos publicados no Scielo (Scientific Electronic Library Online) no período compreendido entre 2001 e 2008, questões sobre a violência sofrida e cometida no ambiente escolar. Simultaneamente apresentaremos uma alternativa para se compreender o fenômeno violência no âmbito da escola, tendo em vista que a alternativa sirva de instrumento formativo para professores e futuros professores. Essa alternativa, por sua vez, vem também de produções sobre a historicidade da nação brasileira.
\end{abstract}

PALAVRAS-CHAVE: Violência escolar. Scielo. Pesquisas. Brasil.

\section{Introdução}

A presença da violência no ambiente escolar, manifestada seja de forma física, simbólica ou verbal, tem marcado por experiências aniquiladoras o cotidiano de alunos e de professores, trazendo danos desastrosos para o resto de suas vidas, sem exagero. Trata-se de acordo com pesquisas que vêm sendo realizadas nas últimas décadas de um fenômeno complexo de difícil apreensão geral. Por exemplo, Ristum e Bastos (2004) evidenciam pelo menos quatro aspectos que denotam a complexidade da violência: 1) a polissemia do conceito e os problemas da definição de violência; 2) a controvérsia na delimitação do objeto da violência; 3) a quantidade, variedade e interação de suas causas e 4) a falta de consenso sobre a natureza da violência.

Neste estudo, procuramos mostrar, a partir de artigos publicados no Scielo (Scientific Electronic Library Online) no período compreendido entre 2001 e 2008, questões sobre a violência sofrida e cometida no ambiente escolar. Simultaneamente apresentamos uma alternativa para se compreender o fenômeno violência no âmbito da escola, tendo em vista que a alternativa sirva de instrumento formativo para professores e futuros professores. Essa alternativa, por sua vez, vem também de produções sobre a historicidade da nação brasileira.

\footnotetext{
${ }^{1}$ UNESP - Universidade Estadual Paulista. Faculdade de Ciências e Letras - Departamento de Didática. Araraquara - São Paulo - Brasil. 14800-901 - marilda@fclar.unesp.br

${ }^{2}$ Mestranda em Educação Escolar. UNESP - Universidade Estadual Paulista. Faculdade de Ciências e Letras - PósGraduação em Educação Escolar. Araraquara - SP - Brasil. 14800-901 - elaine_unesp@hotmail.com
} 
Examinamos quinze artigos publicados acerca do fenômeno da violência em meio escolar no Brasil entre os anos de 2001 e 2008, selecionados na base de dados do Scielo (Scientific Electronic Library Online), a partir do descritivo "violência escolar". Além dos dados que estamos apresentando, fizemos um quadro que contém informações quanto às referências dos artigos, porém, por falta de espaço, neste estudo as referências estão somente no tópico Referências bibliográficas. Porquanto o Scielo disponibiliza textos de distintas áreas do conhecimento acerca do fenômeno da violência em meio escolar no Brasil, objeto de nossa investigação, reitera-se.

Outrossim, para o recorte cronológico, partimos do texto de Marília Pontes Sposito, de 2001, como marco inicial. Trata-se do primeiro balanço das pesquisas sobre as relações entre violência e escola no Brasil realizadas até a entrada do século XXI. Com as informações que extraímos das pesquisas-fonte é que organizamos a alternativa a que nos referimos que consideramos útil para operacionalizar processos formativos de professores.

\section{Violência em meio escolar: o que dizem nossas fontes}

Marília Pontes Sposito (2001) constatou que as pesquisas sobre o fenômeno da violência em meio escolar no Brasil tinham como foco, nos anos de 1980, a análise das depredações e danos aos estabelecimentos escolares; já no período que compreende o final da década de 1990 a 2000, prevalecem como foco nos estudos as relações interpessoais agressivas entre os alunos e os agentes da instituição escolar. Segundo Camacho (apud MARRIEL et al., 2006), há duas manifestações básicas de violência na escola: física (brigas, agressões físicas e depredações) e não-física (ofensas verbais, discriminações, segregações, humilhações e desvalorização com palavras e atitudes de desmerecimento); tendo como protagonistas, ou vítimas, ora os alunos, ora os professores e funcionários.

Neste estudo, utilizamos a categorização segundo Camacho para mostrarmos os problemas de violência identificados em nossas fontes como um todo. Contudo, acrescentamos, extraindo das fontes, o fenômeno Bullying que é uma manifestação de violência praticada entre alunos que pode envolver tanto agressões físicas, quanto não- físicas. Assim, neste estudo, categorizamos os seguintes tipos de violência em ambiente escolar. 


\section{- Bullying}

A crescente presença de bullying nas escolas, de forma sucinta, como comportamentos repetitivos de opressões, agressões, enfim, ações destrutivas de pessoas ou grupos sobre outras pessoas ou grupos, é refletida, sob diferentes enfoques teórico-metodológicos, nas pesquisas de Marriel et al. (2006), Liberal et al. (2005) e Antunes e Zuin (2008).

\section{- Violência física}

O artigo de Zaluar e Leal (2001), Santos (2001), Araújo (2001) e Liberal et al. (2005) sublinham a questão dos impactos do tráfico ou dos bandidos (sic) no âmbito escolar. Segundo esses autores, dentre os reflexos extramuros, tem-se a prática do porte de armas por menores, fator que acarreta, muitas vezes, em morte, repetência e evasão escolar. Ristum e Bastos (2004), Santos (2001), Gonçalves e Sposito (2002), Njaine e Minayo (2003) e Araújo (2001) também afirmam a crescente presença de arma de fogo ou arma branca nas escolas.

Os roubos e depredações aos estabelecimentos de ensino foram abordados por Santos (2001) e Gonçalves e Sposito (2002). Os autores constataram que as medidas de segurança ostensiva não alteraram, de forma significativa, as ocorrências desse tipo. O estudo de Gonçalves e Sposito (2002) revela, também, que em relação às agressões a alunos, “[...] o fenômeno varia de intensidade em cada Estado da federação. Os maiores índices foram registrados no Distrito Federal, em Brasília (58, 6\%), e os mais baixos índices, no Estado de Goiás (8,5\%).”

Além disso, as fontes trazem dados de agressões físicas contra professores. Por exemplo, de acordo com o texto de Njaine e Minayo (2003, p.126), “[...] em Iguatu, foi muito comentada a agressão de uma mãe e de seu filho a uma professora que é muito estimada por todos os jovens, porque esta chamou a atenção desse aluno.” E assim por diante.

\section{- Violência não-física: alunos como agentes protagonistas}

Camacho (2001) estudou as práticas sutis de violência presentes no cotidiano da escola. De acordo com a autora, há, em meio escolar, práticas constantes de violência não-física, verbal e com outras formas de manifestação - como segregação, exclusão, indiferença -, ficando geralmente disfarçadas ou mascaradas.

A pesquisa de Njaine e Minayo (2003, p.121) realizada em escolas públicas e particulares dos Estados do Ceará (cidade de Iguatu), Minas Gerais (Juiz de Fora) e São Paulo (Campinas) 
revela que a "[...] humilhação foi a forma de agressão mais sofrida pelos alunos, seguida pelos furtos, ameaças e destruição dos seus objetos.” Esta pesquisa ressalta, também, a agressividade com que muitos alunos se dirigem aos educadores, levando-os muitas vezes a desistir da profissão.

\section{- Violência não-física: a instituição escolar e seus agentes como protagonistas}

Santos (2001, p.4) ressalta a violência simbólica do saber escolar exercida por professores e funcionários das instituições escolares. Trata-se de “[...] uma relação de poder que impõe um conjunto de valores ao conjunto da população envolvida.”

Segundo Zaluar e Leal (2001), a maior violência que a instituição escolar comete contra os alunos está na sua incapacidade de habilitá-los para enfrentar os problemas do mundo contemporâneo. Além disso, as autoras fazem críticas aos professores que não dominam o conteúdo, que manifestam atitudes agressivas com os alunos, desencadeando problemas de baixa auto-estima nestes e, sobretudo, as manifestações de violência praticada contra os alunos pobres, ora nos processos de avaliação, ora nas formas de relação interpessoais.

A propósito, este fato também foi constatado na pesquisa de Araújo e Pérez (2006, p.461), que, buscando desvelar a violência da escola sobre as crianças, advogam que a democratização do acesso à escola, evidenciada por meio dos dados do MEC, “[...] não representou uma real democratização do acesso ao saber e à cultura letrada.” Essa pesquisa também traz outras manifestações de violência por parte da instituição escolar e seus agentes, mostrando que muitas vezes sua prática pedagógica está arraigada em estereótipos e dispositivos disciplinares.

Marriel et al. (2006) também evidenciam essa questão em sua pesquisa desenvolvida com uma amostra de 1.686 alunos das $7^{\mathrm{a}}$ e $8^{\mathrm{a}}$ séries do Ensino Fundamental e $1^{\mathrm{o}}$ e $2^{\mathrm{o}}$ anos do Ensino Médio do Rio de Janeiro, que demonstraram manifestações constantes de violência na prática dos professores, tais como a imposição de conteúdos insignificantes para os alunos, a aplicação de conteúdos precários, a pressão, baseando-se no poder de atribuir notas, a ignorância dos problemas dos alunos, a forma pejorativa em tratá-los, o fato de dirigir-lhes agressões verbais e expô-los ao ridículo quando estes não compreendem o conteúdo, o que, segundo os autores, desencadeia em baixa auto-estima dos alunos, prejudicando-lhes o desenvolvimento educacional. É importante ressaltar que, em tal trabalho, Marriel et al. (2006, p.46) apontam que "[...] investir na melhoria da relação professor-aluno é um alvo a ser destacado”, tendo em vista o combate à 
violência em meio escolar. Além disso, destacam a importância da formação de professores, pois educadores mal preparados podem acentuar comportamentos arredios nos alunos.

Assim sendo, o texto de Njaine e Minayo (2003) também evidencia que os professores que participaram de sua pesquisa revelaram despreparo para lidar com a realidade violenta. Segundo as autoras, muitos não dão atenção aos alunos ou os agride verbalmente; é constante, também, a violência verbal tendo os funcionários da unidade escolar como protagonistas. Chrispino e Dusi (2008) e Lopes et al. (2008) advogam que é necessária a capacitação/formação de professores e profissionais da escola sobre o tema. Neste sentido, Camacho (2001) aponta falhas na formação dos professores que, para ela, desconhecem os caminhos que devem percorrer e como lidar com a problemática.

As pesquisas analisadas, portanto, trazem contribuições significativas ao estudo do fenômeno da violência em meio escolar, entretanto constatamos lacunas no sentido de não explicitarem de forma objetivada e como os cursos de formação de professores podem possibilitar a seus alunos tipos de procedimentos didático-pedagógicos que os auxiliem a compreender e a evitarem a violência em meio escolar. Sendo assim, em que medida a formação docente pode contribuir para melhorar as relações entre professores e alunos no contexto contemporâneo marcado pela violência? Sob a perspectiva teórica, quais leituras podem dar suporte a professores e futuros professores, sobretudo no sentido de lhes instrumentalizar para evitar a violência em si, para si e para o aluno?

\section{As potencialidades de um curso na minimização da violência em meio escolar}

Diante dos dados extraídos de nossas fontes, constatamos o grande desafio com o qual o professor tem de lidar cotidianamente, pois sua saúde, e até mesmo sua própria vida, estão em risco. De mesma maneira, encontram-se os alunos. Muitas vezes, como mostram as fontes, os alunos sofrem diferentes tipos de violência por parte de seus professores. Nesse sentido, notamos, sobretudo em Zaluar e Leal (2001) e Araújo e Pérez (2006) que, na prática pedagógica de vários professores, há preconceitos e estereótipos afetando o desempenho educacional dos estudantes.

A esse propósito, esta reflexão assevera a potencialidade dos cursos de formação de professores inicial e continuada, no sentido de dar subsídios a esses profissionais, por meio de uma literatura que evidencie a necessidade de pensar a historicidade da realidade social brasileira, na qual o fenômeno violência é tão acentuado. Afinal, é da formação do professor que provém, 
não exclusivamente, mas grande parte da prática pedagógica que será desenvolvida posteriormente. Assim, em consonância com Tessaro (2006, p.118), a prática pedagógica “[...] não deve esquecer a realidade concreta da escola e os determinantes sociais que a circundam. [...] os cursos de formação devem assumir o compromisso de oferecer aos futuros professores uma visão crítica de suas ações, conceitos e preconceitos”.

Propomos, portanto, um tipo de bibliografia a ser desenvolvida em algum momento da formação dos professores que mostre o contexto nacional saindo de dentro para fora, isto é, saindo do âmago de nossa nacionalidade. Dentre as referências possíveis destacamos: Brasil: Mito Fundador e Sociedade Autoritária, de Marilena Chauí (2000); O Povo Brasileiro (2000), de Darcy Ribeiro; Cabeça de Porco (2005), de Celso Athaide, Luiz Eduardo Soares e MV BILL; A Palavra é Escola... (1992), coletânea de contos reunidos por Manuel da Cunha Pereira que tem como temática a escola. São, porquanto, fontes de estudo oriundas de diferentes áreas do saber que permitem, direta e indiretamente, a compreensão da constituição da nação brasileira, bem como de seus redutos particulares, permitindo ao professor, ou futuro professor, uma reflexão sobre as características da violência no contexto brasileiro a partir de suas estruturas antropológicas, sociais, culturais e econômicas.

Essa bibliografia, que já experimentamos em sala de aula com o objetivo de fundamentar uma reflexão sobre o contexto brasileiro $^{3}$, tem a fertilidade de mostrar a seus leitores a complexidade do fenômeno violência no Brasil como um todo e, em particular, em meio escolar. Nesse sentido, em Veiga apud (TESSARO, 2004, p.124) “[...] falta ao professor uma consciência das finalidades da educação, de suas relações com a sociedade, dos meios necessários para efetivação das atividades educacionais, [...]”. É justamente nessa direção que este referencial teórico-metodológico coloca o professor.

No texto Brasil: Mito Fundador e Sociedade Autoritária, a filósofa Marilena Chaú́ evidencia de forma profunda como o Brasil se desenvolveu historicamente enquanto uma sociedade autoritária. O objetivo de Chauí é explicitar que o conceito teórico 'mito fundador' é o responsável pela representação otimista que a maioria dos brasileiros tem de seu país e de si mesmo quando, no entanto, trata-se de uma sociedade com infinitas mazelas. Em síntese, a autora mostra que o mito fundador e suas representações são construções históricas, que têm uma finalidade ideológica; sua

\footnotetext{
${ }^{3}$ Trata-se da disciplina Procedimentos teórico-metodológicos na produção da pesquisa: a literatura como fonte, optativa oferecida aos alunos do Programa de Pós-Graduação em Educação Escolar - FCL/Car, ministrada pela professora Livre-docente Marilda da Silva.
} 
função é a de mascarar a realidade conflituosa contribuindo para o fortalecimento da violência exercida por uma classe sobre a outra, pois não revela as vicissitudes de uma realidade profundamente marcada pela desigualdade, discriminação, dominação e exploração da classe dominante sobre as classes populares.

Numa perspectiva semelhante, ao estudar a história do ponto de vista dos dominados, o antropólogo Darcy Ribeiro traz importantes contribuições acerca do Brasil, que também podem subsidiar a prática pedagógica dos professores. Segundo Darcy Ribeiro (2000, p.168), “vivemos praticamente em estado de guerra latente.” O mesmo autor aponta que o país foi estruturado baseado numa "racionalidade que a uns privilegia e enobrece, fazendo-os donos da vida, e aos demais subjuga e degrada, como objeto de enriquecimento alheio” (RIBEIRO, 2000, p.196). Dessa forma, a única saída encontrada por muitos é a violência. Afinal, como diria Pinheiro (apud RISTUM; BASTOS, 2004, p.236), “em uma sociedade desigual o crime é um meio para a mobilidade social”, e os professores precisam compreender isso.

Cabeça de Porco permite que o professor se aproxime da realidade do tráfico de drogas, da violência e do descaso nos quais vivem os moradores da realidade subumana das favelas brasileiras. O mais importante desse livro é que os autores evidenciam o lado humano dos moradores das favelas, mostram a luta destes por uma vida digna em um sistema que insiste em desumanizá-los.

Por último, A Palavra é Escola... traz belíssimos contos da literatura brasileira, que mostram as relações interpessoais no âmbito escolar de forma certamente inédita para o futuro professor.

Um referencial como este, talvez, ajude os professores a não serem preconceituosos ao exercerem seu ofício. Nesse sentido, acreditamos que o entendimento da realidade social deve ser dado ao professor ao longo de sua formação para que ele compreenda a realidade do aluno e não exerça uma prática pedagógica alicerçada no “senso comum”. Sendo assim, é necessário que

O futuro professor se capacite, para, em sua prática docente, compreender o universo cultural do aluno, a fim de que, juntos, a partir do que conhecem, venham a se debruçar sobre os desafios que o mundo lhes apresenta, procurando respondê-los, e, nesse esforço, produzam novos saberes (MOREIRA apud TESSARO, 2004, p.125). 
Propor o uso de uma bibliografia como essa significa concordar com a perspectiva adotada por Angel Pino (2007, p.772), segundo a qual "se a educação não é a solução para acabar com a violência, sem educação a violência não tem solução, nem a curto nem a longo prazo”. Trata-se de um material pedagógico, a nosso juízo, que leva a uma atividade docente, acima de tudo, mais humana e mais eficaz do ponto de vista da participação da educação na construção da nação brasileira que seja satisfatória a seus agentes diretos, neste caso alunos e professores.

\title{
Considerações finais
}

Tendo em vista as constatações e reflexões apresentadas neste estudo, buscou-se evidenciar a importância do uso de uma bibliografia nos cursos de formação de professores que trate da construção da nacionalidade brasileira, tendo em vista compreender a constituição da violência no país e simultaneamente desenvolver instrumentos cognitivos e relacionais para que sejam eficazes na erradicação da violência não apenas em meio escolar, mas sim na sociedade como um todo. Esta é apenas uma sugestão que vem dando certo na formação de futuros pesquisadores na Faculdade de Ciências e Letras UNESP Araraquara - SP.

\section{VIOLENCE IN THE BRAZILIAN SCHOOL ENVIRONMENT: A FORMATIVE ALTERNATIVE FOR NEW AND VETERAN TEACHERS}

\begin{abstract}
The present work is intended to show the main issues associated to people who committed or suffered violence in the school environment by means of published articles in the Scielo database (Scientific Electronic Library Online) within the period from 2001 to 2008. An alternative will be simultaneously shown in order to understand the violence phenomenon in the school environment. Such alternative is believed to act as a formative instrument for new and veteran teachers, since it also comes from reports on the history of the Brazilian Nation.
\end{abstract}

KEYWORDS: School violence. Scielo. Survey. Brazil.

\section{REFERÊNCIAS}


ANTUNES, D. C.; ZUIN, A. Á. S. Do bullying ao preconceito: os desafios da barbárie à educação. Revista Psicologia e Sociedade, Porto Alegre, v.20, n.1, jan./abr. 2008.

ARAÚJO, C. As marcas da violência na constituição da identidade de jovens da periferia. Revista Educação e Pesquisa, São Paulo, v.27, n.1, p.141-160, jan./jun. 2001.

ARAÚJO, M. da S.; PÉREZ, C. L. V. Um jogo de luz e de sombras: lógicas de ação no cotidiano escolar. Revista Brasileira de Educação, Rio de Janeiro, v.11, n.33, p.461-469, set./dez. 2006.

ATHAYDE, C.; SOARES, L. E.; MV BILL. Cabeça de porco. Rio de Janeiro: Objetiva, 2005.

CAMACHO, L. M. Y. As sutilezas das faces da violência nas práticas escolares de adolescentes. Revista Educação e Pesquisa, São Paulo, v.27, n.1, p.123-140, jan./jun. 2001.

CHAUÍ, M. Brasil: mito fundador e sociedade autoritária. São Paulo: Fundação Perseu Abramo, 2000.

CHRISPINO, A.; DUSI, M. L. H. MASOTTI. Uma proposta de modelagem de política pública para a redução da violência escolar e promoção da Cultura da Paz. Revista Ensaio: avaliação e políticas públicas em educação, Rio de Janeiro, v.16, n.61, p.597-624, out./dez. 2008.

GONÇALVES, L. A. O.; SPOSITO, M. P. Iniciativas públicas de redução da violência escolar no Brasil. Revista Cadernos de Pesquisa, São Paulo, n.115, p. 101-138, mar. 2002.

LIBERAL, E. F. et al. Escola segura. Jornal de Pediatria, Porto Alegre, v.81, n.5, p.155-163, nov. 2005.

LOPES, R. E. et al. Juventude pobre, violência e cidadania. Revista Saúde e Sociedade, São Paulo, v.17, n.3, p.63 - 76, 2008.

MARRIEL, L. C. et al. Violência escolar e auto-estima de adolescentes. Revista Cadernos de Pesquisa, São Paulo, v.36, n.127, p.35-50, jan./abr. 2006.

NJAINE, K.; MINAYO, M. C. de S. Violência na escola: identificando pistas para a prevenção. Revista Interface (Botucatu), Botucatu, v.17, n.13, p.119-134, ago. 2003.

PEREIRA, M. C. A palavra é escola... São Paulo: Spicione, 1992.

PINO, A. Violência, educação e sociedade: um olhar sobre o Brasil contemporâneo. Revista Educação e Sociedade, Campinas, v.28, n.100, p.763-785, out. 2007. 
RIBEIRO, D. O povo brasileiro: formação e sentido do Brasil. São Paulo: Companhia das Letras, 2000.

RISTUM, M.; BASTOS, A. C. de S. Violência urbana: uma análise dos conceitos de professores do ensino fundamental. Revista Ciência Saúde Coletiva, Rio de Janeiro, v.9, n.1, p.225-239, 2004.

SANTOS, J. V. T. dos A violência na escola: conflitualidade social e ações civilizatórias. Revista Educação e Pesquisa, São Paulo, v.27, n.1, p.105-122, jan./jun. 2001.

SPOSITO, M. Um breve balanço da pesquisa sobre violência escolar no Brasil. Revista Educação e Pesquisa, São Paulo, v.27, n.1, p.87-104, 2001.

TESSARO, A. Estigma e preconceitos como expressões da exclusão escolar: uma questão na formação de professores? 2004. Dissertação (Mestrado em Educação) - Universidade Estadual de Maringá, Maringá, 2004.

ZALUAR, A.; LEAL, M. C. Violência extra e intramuros. Revista Brasileira de Ciências Sociais, São Paulo, v.16, n.45, p.145-164, fev. 2001. 